\title{
Prevalence of molecular markers of anti-malarial drug resistance in Plasmodium vivax and Plasmodium falciparum in two districts of Nepal
}

\author{
Samir Ranjitkar ${ }^{1}$, Mette L Schousboe ${ }^{1}$, Thomas Thyge Thomsen ${ }^{1}$, Madhav Adhikari ${ }^{2}$, Christian MO Kapel ${ }^{3}$, \\ Ib C Bygbjerg ${ }^{1}$ and Michael Alifrangis ${ }^{1 *}$
}

\begin{abstract}
Background: Sulphadoxine-pyrimethamine (SP) and chloroquine (CQ) have been used in treatment of falciparum and vivax malaria in Nepal. Recently, resistance to both drugs have necessitated a change towards artemisinin combination therapy (ACT) against Plasmodium falciparum in highly endemic areas. However, SP is still used against $P$. falciparum infections in low endemic areas while CQ is used in suspected cases in areas with lack of diagnostic facilities. This study examines the prevalence of molecular markers of $\mathrm{CQ}$ and $\mathrm{SP}$ resistance in P. falciparum and Plasmodium vivax to determine if high levels of in vivo resistance are reflected at molecular level as well.
\end{abstract}

Methods: Finger prick blood samples $(n=189)$ were collected from malaria positive patients from two high endemic districts and analysed for single nucleotide polymorphisms (SNPS) in the resistance related genes of $P$. falciparum and P. vivax for CQ (Pfcrt, Pfmdr1, Pvmdr1) and SP (Pfdhfr, Pfdhps, Pvdhfr), using various PCR-based methods.

Results and discussion: Positive $P$. vivax and $P$. falciparum infections were identified by PCR in 92 and 41 samples respectively. However, some of these were negative in subsequent $P C R s$. Based on a few $P$. falciparum samples, the molecular level of CQ resistance in $P$. falciparum was high since nearly all parasites had the Pfcrt mutant haplotypes CVIET (55\%) or SVMNT (42\%), though frequency of the Pfmdr1 wild type haplotype was relatively low (35\%). Molecular level of SP resistance in P. falciparum was found to be high. The most prevalent Pfdhfr haplotype was double mutant CNRNI (91\%), while frequency of Pfdhps double mutant SGEAA and AGEAA were 38\% and 33\% respectively. Combined, the frequency of quadruple mutations (CNRNI-SGEAA/AGEAA) was 63\%. Based on P. vivax samples, low CQ and SP resistance were most likely due to low prevalence of Pvmdr1 Y976F mutation (5\%) and absence of triple/quadruple mutations in Pvdhfr.

Conclusions: Based on the limited number of samples, prevalence of CQ and SP resistance at molecular levels in the population in the study area were determined as high in P. falciparum and low in P. vivax. Therefore, CQ could still be used in the treatment of $P$. vivax infections, but this remains to be tested in vivo while the change to ACT for $P$. falciparum seems justified.

\section{Background}

Malaria is one of the major health problems in SouthEast Asia where 1.3 billion people (76\% of total population) are at risk, causing around 120,000 deaths yearly [1]. Plasmodium vivax malaria is the most widespread and prevalent in this region but large knowledge gaps

\footnotetext{
* Correspondence: micali@sund.ku.dk

${ }^{1}$ Centre for Medical Parasitology, Department of International Health, Immunology and Microbiology, Faculty of Health Sciences, University of Copenhagen, Copenhagen, Denmark

Full list of author information is available at the end of the article
}

still exits that preventing the assessment of the technical feasibility of its elimination still exist [2]. In Nepal, roughly $80 \%$ ( 22.5 million) of the population lives in malaria endemic areas of which seven million reside in highly endemic areas [3]. P. vivax is the predominant species that causes around $80-90 \%$ of the total malaria cases while Plasmodium falciparum is the main cause of malaria epidemics in Nepal [4]. Malaria transmission may occur throughout the year but mostly from March to November with peaks in June, July and August [5].

\section{C) Biomed Central}


Chloroquine (CQ) is the first-line drug for the treatment of $P$. vivax infections as well as for the treatment of suspected $P$. falciparum infections in situations where diagnosis is unavailable; sulphadoxine-pyrimethamine (SP) has been the drug of choice for laboratory confirmed uncomplicated P. falciparum infections. Recently, artemisinin combination therapy (ACT) was introduced in 13 high endemic areas, replacing SP, as treatment for laboratory confirmed uncomplicated $P$. falciparum due to reports of high SP resistance [4].

Anti-malarial drugs have been one of the most important tools in the control of malaria over the last 50 years $[6,7]$. However, a major impediment to this strategy is the capacity of the parasites to develop drug resistance. This resistance has spread almost globally with regard to CQ and SP $[7,8]$. In Nepal, CQ resistance to P. falciparum was first observed in 1984, then in 1986, 1987 and 1988 [9]. CQ resistance in $P$. vivax has not been recorded. SP resistance in $P$. falciparum was first recorded in 1996 and then again in $2003[9,10]$. These studies were based on reports of treatment failures. Molecular markers of drug resistance, which are now commonly applied as an adjunct in the surveillance of anti-malarial drug resistance, have had only been used limited in Nepal. The advantage of using molecular markers of drug resistance is that the level of drug resistance can be studied retrospectively, such as after a drug has been abandoned due to reports of high levels of drug resistance in vivo.

CQ resistance is associated with single nucleotide polymorphisms (SNPs) in the $P$. vivax multidrug resistance gene 1 (Pvmdr1) at codon (c) 976 (Y976F) [11] and the $P$. falciparum chloroquine resistance transporter gene (Pfcrt) at c76 (K76T) [12,13]. In P. falciparum, certain mutant haplotypes at c72-76 are highly prevalent globally, namely CVIET and SVMNT [14]. Additionally, SNPs at c86, c184 and c1246 in P. falciparum $m d r-1$ (Pfmdr1) have been associated with CQ resistance $[6,15]$. However, its role is considered as modulatory when SNPs in Pfmdr1 occur with the Pfcrt K76T mutation [7].

Resistance to SP is conferred by SNPs in the genes coding for dihydrofolate reductase $(d h f r)$ and dihydropteroate synthetase (dhps) in both $P$. vivax [16,17] and $P$. falciparum $[18,19]$. Although SP is not used deliberately against $P$. vivax infections, exposure can occur because mixed infections are common and often misdiagnosed in Asia [20-22]. In P. vivax, SNPs at c57 (F57L), c58 (S58R), c61 (T61M) and c117 (S117N) in Pvdhfr are associated with pyrimethamine (PYR) resistance $[23,24]$. For P. falciparum, SNPs at c51 (N51I), c59 (C59R), c108 (S108N) and c164 (I164L) of Pfdhfr are associated with PYR resistance $[7,25]$ while sulphadoxine resistance is associated with SNPs at c436 (S436A), c437 (A437G), c540 (K540E), c581 (A581G) and c613 (A613S/T) [8,25].
In Nepal, a limited study of molecular markers of antimalarial drug resistance only in $P$. falciparum has been carried out [26]. Therefore, in light of the changing drug policy in Nepal towards using ACT; artemetherlumefantrine (AL) in some areas for P. falciparum and to fill some of the gaps in the knowledge of resistance to commonly used anti-malarials, the present study investigated the prevalence of molecular markers of anti-malarial drug resistance in both species by analysing the SNPs of Pfcrt, Pfmdr1, Pfdhfr and Pfdhps in P. falciparum and Pvmdr1 and Pvdhfr in P. vivax using samples from patients living in two highly endemic districts of Nepal.

\section{Methods}

\section{Sample collection}

Ethical clearance was obtained from the Nepal Health Research Council, Kathmandu, for the study (Ref. No. 266). After obtaining informed consent from either the patient or legal guardian, blood samples were collected from patients attending private or government hospitals or health posts in Jhapa $(n=146)$ and Banke $(n=43)$ districts in Eastern and Western Nepal, respectively (Figure 1). Malaria is highly endemic in both districts and are two of the 13 districts where ACT (AL) was implemented in 2004 [4]. These districts share borders with the Indian states of Uttar Pradesh, Bihar and Assam where malaria is endemic [5]. Finger prick blood samples were collected either on Whatman no. 3 filter paper or as blood smear slides from malaria positive patients confirmed by microscopy or rapid diagnostic test.

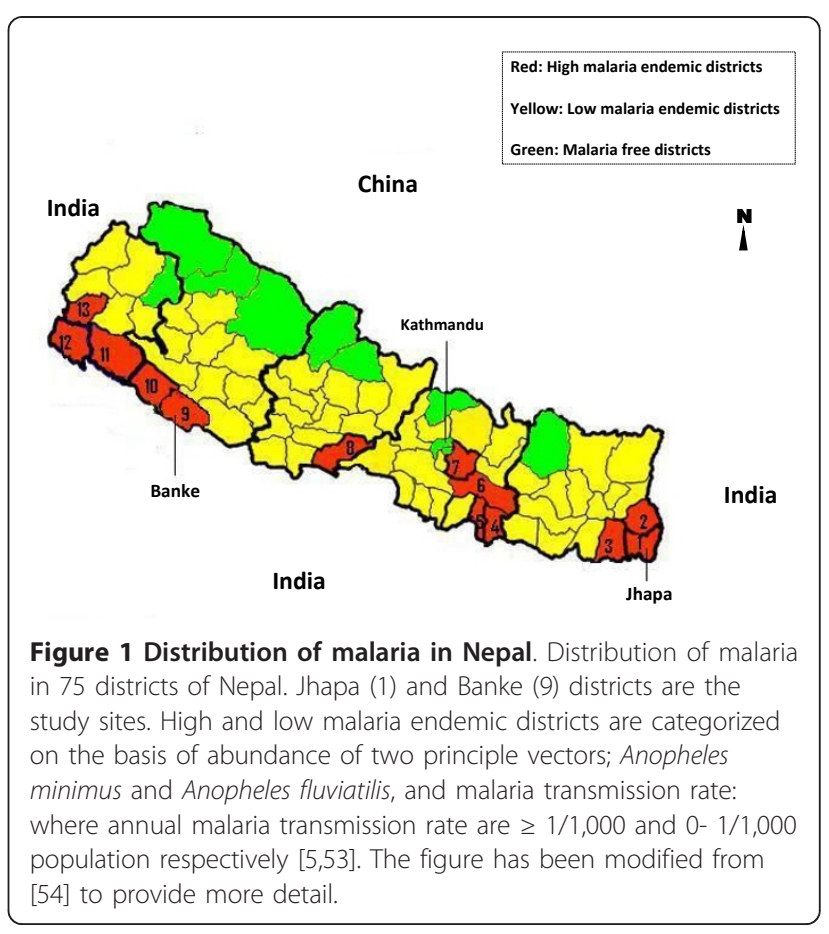




\section{Genetic characterization of the parasites}

Extraction of DNA from filter paper and blood smear slides were done by chelex method as described in [27] and [28] respectively. Plasmodium species (either vivax or falciparum) were differentiated by nested polymerase chain reaction (PCR) as in [29] and identification of Plasmodium malariae and Plasmodium ovale were done as previously [30]. Analysis of SNPs at Pvmdr1 was done by sequencing the nested PCR products as in [31]. Analysis of SNPs at Pvdhfr was performed by sequence specific oligonucleotide probes- enzyme-linked immunosorbent assay (SSOP-ELISA) as in [32] and for Pfcrt, Pfdhfr and Pfdhps, analysis were done by SSOP-ELISA as previously described in [33]. Finally, Pfmdr1 was analysed by PCR-restriction fragment length polymorphism (RFLP) as described elsewhere [34,35].

\section{Results}

Of the 189 samples, PCR identified 113 samples (60\%) positive for Plasmodium, of which 72 (64\%) and 21 (19\%) samples were $P$. vivax and $P$. falciparum respectively while $20(17 \%)$ of the samples carried mixed $P$. falciparum/P. vivax infections (Table 1). No $P$. malariae or P. ovale infections were detected. Positive samples from Banke were few $(11 \%, \mathrm{n}=12)$ when compared to Jhapa $(89 \%, \mathrm{n}=101)$ and was pooled since no apparent differences were observed between the sampling sites. The species PCR positive samples were further categorized according to type of infection, gender and age group. The highest prevalence of malaria was found in males $(85 \%, \mathrm{n}=96)$ and the prevalence of infections were highest in the age group of $21-40$ years $(66 \%, n=75)$ followed by $0-20$ years $(18 \%$, $\mathrm{n}=20)$ (Table 1).

\section{Prevalence of SNPs in Pfcrt}

The prevalence of haplotypes at c72-76 could be determined for 31 out of 41 P. falciparum positive samples including mixed haplotypes $(n=2)$. The mutant haplotypes CVIET and SVMNT were identified in 55\% ( $\mathrm{n}=$ $17)$ and $42 \%(n=13)$ of samples respectively while $10 \%$

Table 1 Distribution of PCR positive samples from Jhapa and Banke districts in Nepal

\begin{tabular}{|c|c|c|c|c|c|c|}
\hline \multirow{2}{*}{$\begin{array}{l}\text { Type of } \\
\text { infection }\end{array}$} & \multicolumn{2}{|l|}{ Gender } & \multirow[t]{2}{*}{ Total } & \multicolumn{3}{|c|}{ Age group } \\
\hline & Male & Female & & $0-20$ yrs & $21-40$ yrs & $\geq 41 \mathrm{yrs}$ \\
\hline Pv & $61(89 \%)$ & $8(11 \%)$ & $72(64 \%)$ & $11(15 \%)$ & 49(68\%) & $12(17 \%)$ \\
\hline Pf & $14(67 \%)$ & $7(33 \%)$ & 21(19\%) & $7(33 \%)$ & $13(62 \%)$ & $1(5 \%)$ \\
\hline$P v+P f$ & 18(90\%) & $2(10 \%)$ & $20(17 \%)$ & $2(10 \%)$ & $13(65 \%)$ & $5(25 \%)$ \\
\hline Total & $96(85 \%)$ & $17(15 \%)$ & 113 & $20(18 \%)$ & $75(66 \%)$ & $18(16 \%)$ \\
\hline
\end{tabular}

Distribution of 113 positive samples based on species PCR according to infected species: $\mathrm{Pv}=P$. vivax, $\mathrm{Pf}=P$. falciparum and $\mathrm{Pv}+\mathrm{Pf}=$ mixed infections, along with the gender and age group of the subjects. samples $(\mathrm{n}=3)$ contained the wild type CVMNK (Figure 2).

\section{Prevalence of SNPs in Pfmdr1}

SNPs were examined at c86, c184 and c1246 in 33, 32 and 30 samples respectively. The prevalence of mutations in the Pfmdr1 gene were N86Y $(33 \%, \mathrm{n}=11)$ and Y184F (44\%, $\mathrm{n}=14$ ) including mixed infections $(\mathrm{n}=1$ for $\mathrm{c} 86$ and $n=3$ for c184) while only wild type D1246 was observed $(n=30)$. Haplotypes could be constructed for three codons in 26 samples with different haplotypes identified: NYD (35\%, $\mathrm{n}=9)$, NFD $(35 \%, \mathrm{n}=9)$ and YYD $(30 \%, \mathrm{n}=8)$ (Figure 3).

\section{Prevalence of SNPs in Pfdhfr and Pfdhps}

For Pfdhfr, SNPs were examined at c50, c51, c59, c108 and $\mathrm{c} 164$ in 32 samples. Mutations were determined at N51I, C59R and S108N with the prevalence of $6 \%$ ( $\mathrm{n}=$ $2)$, $97 \%(n=31)$ and $97 \%(n=31)$, respectively while only wild types were detected at c50 $(\mathrm{n}=32)$ and $\mathrm{c} 164$ $(\mathrm{n}=32)$. Haplotypes could be constructed for 32 samples and determined as either double mutants CNRNI $(91 \%, \mathrm{n}=29)$, triple mutants CIRNI $(6 \%, \mathrm{n}=2)$ and wild type CNCSI $(3 \%, \mathrm{n}=1)$ (Figure 4$)$.

SNPs at c436, c437, c540 were examined in 30 samples and at c581 and c613 in 31 samples of the Pfdhps gene, respectively. Majority of infections carried mutations at A437G $(77 \%, \mathrm{n}=23), \mathrm{K} 540 \mathrm{E}(70 \%, \mathrm{n}=21)$ and S436A (33\%, $\mathrm{n}=10$ ) while the A581G mutation was found in $3 \%$ of samples $(n=1)$ and wild type was observed only at c613 $(n=31)$. Haplotypes could be constructed for 28 samples, of which double mutants SGEAA (38\%, $\mathrm{n}=10)$ and AGEAA $(33 \%, \mathrm{n}=9)$ were the major haplotypes, followed by wild type SAKAA

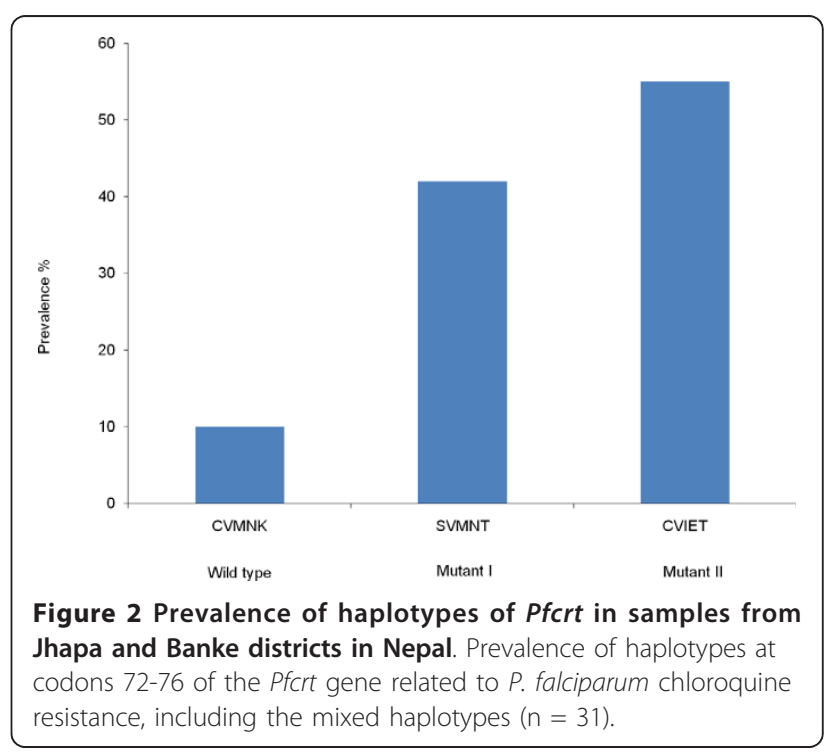




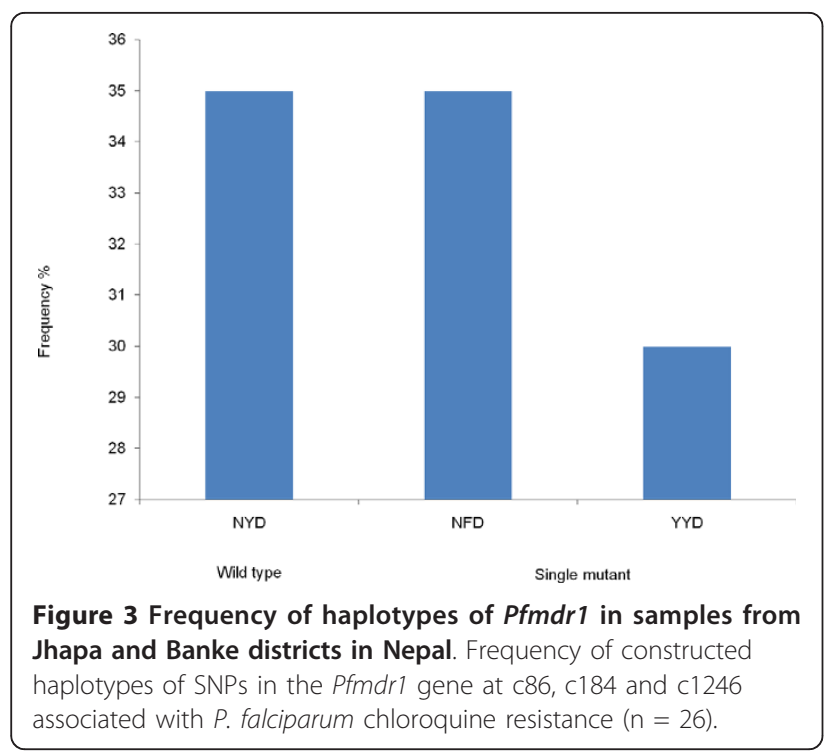

$(21 \%, \mathrm{n}=6)$, single mutant SGKAA $(7 \%, \mathrm{n}=2)$ and double mutant SGKGA $(4 \%, \mathrm{n}=1)$ (Figure 5).

When both $P f d h f r$ and Pfdhps haplotypes were jointly examined, haplotypes could be constructed for 27 samples. The main haplotypes were the quadruple mutant haplotypes CNRNI/SGEAA (33\%, $\mathrm{n}=9$ ) and CNRNI/ AGEAA $(30 \%, \mathrm{n}=8)$, whereas the quintuple mutant haplotypes were determined low; CIRNI/AGEAA (4\%, $\mathrm{n}=1)$ and CIRNI/SGKAA $(4 \%, \mathrm{n}=1)$.

\section{Prevalence of SNPs in Pvmdr1}

Only a fraction of samples $(n=47)$ were sequenced by alignment of DNA sequence with the wild type Salvador 1 as reference strain and out of these, 39 samples had

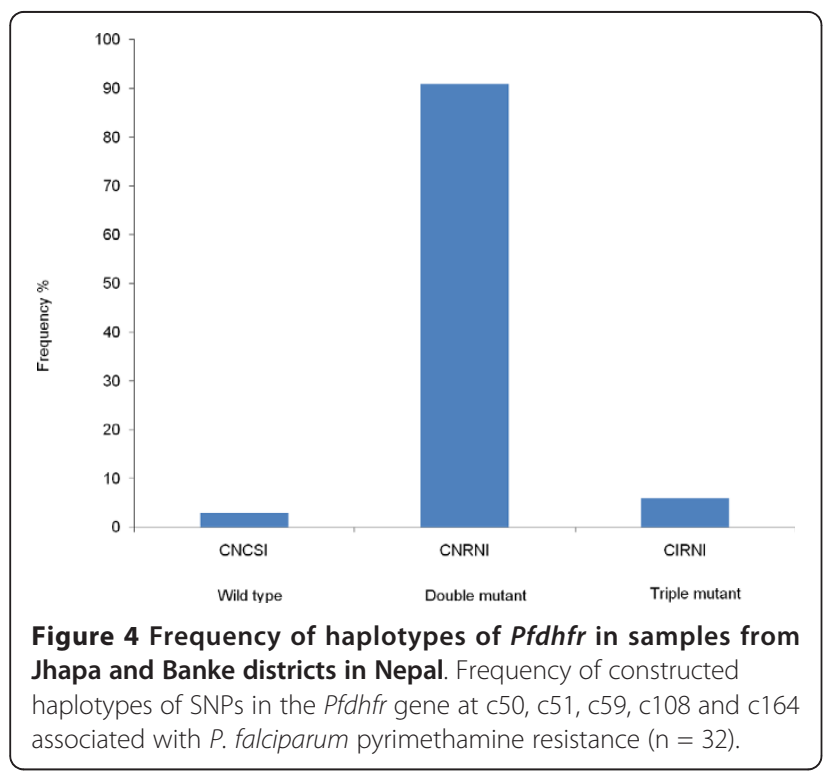

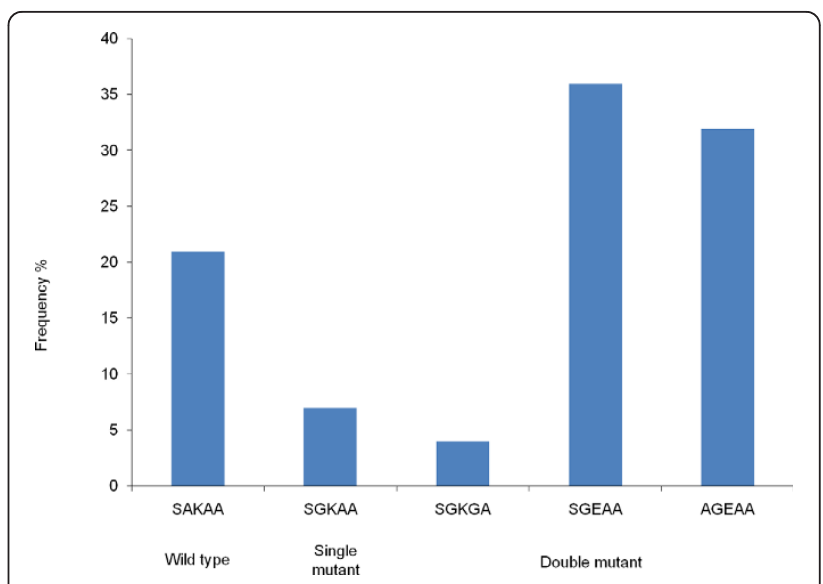

Figure 5 Frequency of haplotypes of Pfdhps in samples from Jhapa and Banke districts in Nepal. Frequency of constructed haplotypes of SNPs in the Pfdhps gene at c436, c437, c540, c581 and c613 linked with $P$. falciparum sulphadoxine resistance $(n=28)$. satisfactory results. Only a fragment of 784 bp covering the codons 958, 976 and 1076 of the Pvmdr1 gene had been sequenced. A novel mutation was identified at T958M in all samples while F1076L was observed in 37 samples (95\%) and Y976F was only identified in two samples (5\%). Including the T958M mutation in constructing haplotypes for c958, c976 and c1076, the most frequent haplotype was the double mutant haplotype MYL $(82 \%, n=32)$, whereas the single mutant MYF and the triple mutant MFL haplotypes were determined in $13 \%(\mathrm{n}=5)$ and $5 \%(\mathrm{n}=2)$ of the cases, respectively (Figure 6). Finally, novel SNPs were observed in two samples; one sample was found to contain a TTT to TCT mutation at c979 (F979S), and an ATG to GTG mutation at c980 (M980V). Further, one sample contained an AGT to AAT mutation at c1080 (S1080N).

\section{Prevalence of SNPs in Pvdhfr gene}

SNPs were observed at c57, c58, c61 in 63 samples and at c117 in 65 samples respectively. Pvdhfr mutations were identified at S58R $(68 \%, \mathrm{n}=43)$ followed by S117N/T $(54 \%, \mathrm{n}=35)$ and F57L $(11 \%, \mathrm{n}=7)$, whereas only wild type was determined at c61. Haplotypes could be constructed for 55 samples and the major haplotypes were the double mutant FR2TN $(47 \%, \mathrm{n}=26)$ and wild type FSTS $(27 \%, \mathrm{n}=15)$. Single mutant haplotypes FR1TS $(9 \%, \mathrm{n}=5)$, FR2TS $(4 \%, \mathrm{n}=2)$ \& FSTT $(2 \%, \mathrm{n}=1)$ and double mutant haplotypes L2R1TS $(9 \%, \mathrm{n}=5)$ \& L2STN $(2 \%, \mathrm{n}=1)$ were also determined while triple and quadruple mutant haplotypes were not identified (Figure 7).

\section{Discussion}

Several therapeutic efficacy studies were carried out in Nepal to determine the efficacy of currently used 


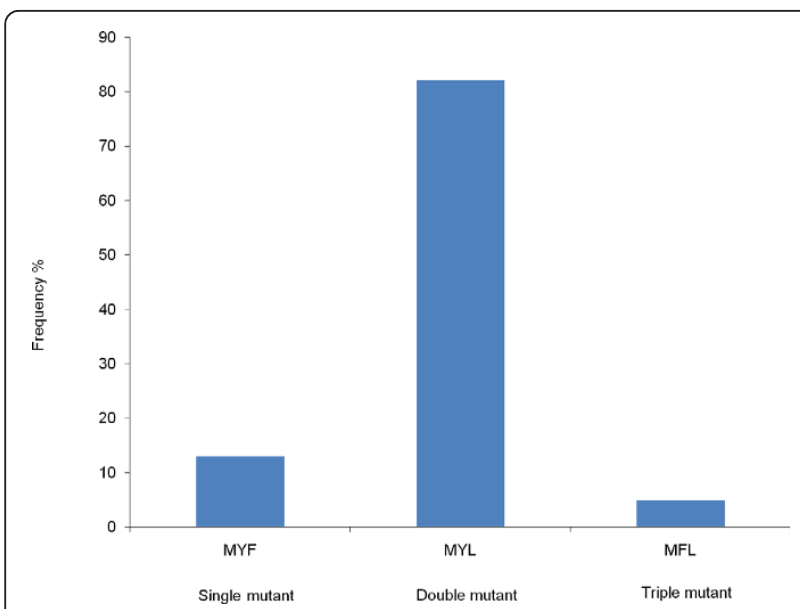

Figure 6 Frequency of haplotypes of Pvmdr1 in samples from Jhapa and Banke districts in Nepal. Frequency of constructed haplotypes of SNPS in the Pvmdr1 gene at C958, c976 and c1076 associated with $P$. vivax chloroquine resistance $(n=39)$.

anti-malarial drugs. For P. falciparum, studies done from 1984 to 1990 had shown 38\% in vivo resistance to CQ. Similarly, SP efficacy studies conducted between 1996 to 2000 showed 57-73\% treatment failures in $P$. falciparum infections [36]. Contrarily, a trial performed in 2005 in Jhapa showed only 12\% SP treatment failure [26]. In Nepal, changes in anti-malarial drug policies have been based on declining efficacy of first line drugs when the therapeutic efficacy fell below 90\% [4]. In line with this, AL was introduced against $P$. falciparum in 2004 in 13 highly endemic districts. SP is still the first line of treatment in the other 52 endemic districts, however, ACT will gradually replace $\mathrm{SP}$ in the near future [4].

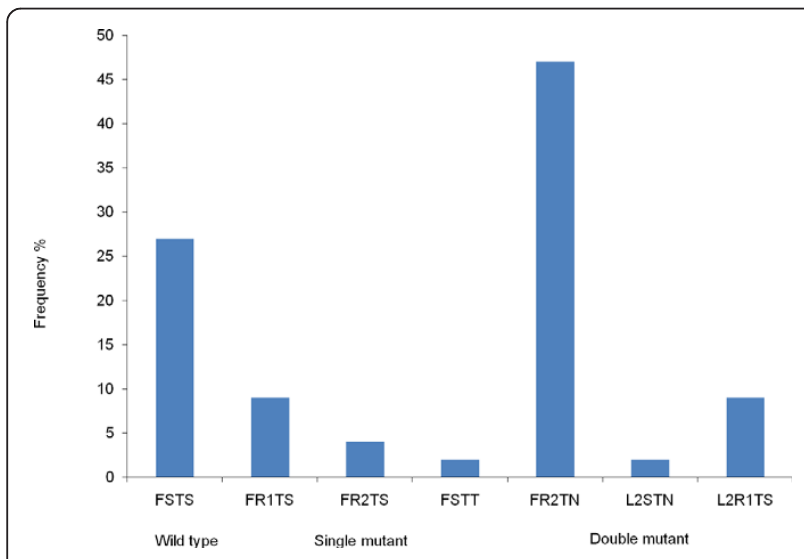

Figure 7 Frequency of haplotypes of Pvdhfr in samples from Jhapa and Banke districts in Nepal. Frequency of constructed haplotypes of SNPs in the Pvdhfr gene at c57, c58, c61 and c117 linked with $P$. vivax pyrimethamine resistance $(n=55)$.
This study determined CQ and SP resistance at molecular level to explore whether the high level of in vivo CQ and SP resistance previously found in Nepal resulting in the recent policy change, is reflected at molecular level as well. Polymorphisms related to CQ resistance in $P$. falciparum were determined in both Pfcrt and Pfmdr1. Combined, the Pfcrt mutant haplotypes CVIET (55\%) and SVMNT (42\%) were determined in a total of $97 \%$ of samples indicating high levels of CQ resistance. These haplotypes were also the most common haplotype determined from the Indian state of Assam (33\% CVIET and 62\% SVMNT) in 2006 [37].

Studies done in Malawi [38] and Tanzania [39] had shown the re-emergence of CQ sensitive $P$. falciparum populations after the withdrawal of CQ as a first line drug. However, this was not observed here, most probably due to the current anti-malarial drug policy of Nepal which recommends CQ for laboratory unconfirmed P. falciparum infection [4]. Regarding Pfmdr-1, this study found a high prevalence of wild types N86 (67\%), Y184 (56\%) and D1246 (100\%). Further, 35\% of the constructed haplotypes were the haplotype NFD. This haplotype has previously been implied as a marker of emerging AL tolerance $[35,40]$. Therefore, it is important to continue the monitoring of this particular marker in Nepal now with AL as the first-line treatment in highly endemic areas.

Studies have indicated that Y976F is the most important marker of CQ resistance and F1076L of lesser importance [11,31,41]. The analysis of Pvmdr1 identified a novel mutation at T958M, which has only been reported in samples from Madagascar [42] and its role in CQ resistance is unknown. Likewise, mutation at Y976F was determined only in two samples (5\%). This suggests the presence of limited prevalence of CQ resistant haplotypes in $P$. vivax population. Finally, SNPs at c979, c980 and c1080 were observed, which have not been described elsewhere and the implications of these are unknown.

Regarding SP resistance in P. falciparum, SNPs at c51, c59 and c108 of Pfdhfr were identified. The most frequent mutant haplotype was the double mutated CNRNI (91\%), which was also the most frequent haplotype determined at $64 \%$ from Jhapa in 2005 [26]. Thus, it seems that the prevalence of double mutant haplotype has increased. Furthermore, in 2003/2004, the CNRNI haplotype was the most frequent haplotype determined at $50-91 \%$ and $74-80 \%$ from Utter Pradesh and Assam in India, respectively $[43,44]$. Likewise, the triple mutated CIRNI was detected at low prevalence $(6 \%)$ in the current study and in concordance with the previous study done in Jhapa (prevalence of 10\% and 3\% in 2002 and 2005 respectively) [26]. Further, CIRNI was also determined low in samples from Utter Pradesh (5\%) and 
Assam (10\%) in 2003 [43,44], which indicates a low but consistent prevalence of the triple mutant haplotypes in the region. For Pfdhps, SGEAA (38\%) and AGEAA (33\%), the haplotypes that have been associated with treatment failure of SP [45] were the most prevalent in this study. In the study done in Assam in 2003/2004, SGEAA and AGEAA were determined in 2-6\% and 11$17 \%$ of the samples, respectively [43,44]. This may suggest an increase of sulphadoxine resistant haplotypes in the region.

For Pfdhfr and Pfdhps combined, both quadruple (double mutations in Pfdhps and Pfdhps) and quintuple mutations (triple mutations in Pfdhfr and double mutations in Pfdhps) have been associated with treatment failures $[43,46,47]$. The present study determined quadruple mutations in $63 \%$ of samples. Further, the low prevalence $(17 \%)$ of CNRNI-SGEAA/AGEAA in Assam in $2003[43,44]$ may point towards the increase of prevalence of quadruple mutations in the region. Thus, this high prevalence may imply a high risk of SP treatment failure, which is in concordance with two previous studies done in Jhapa that recorded $12 \%$ and $21 \%$ treatment failures of SP [26,48].

Although SP is not used deliberately against $P$. vivax infections in Nepal, P. vivax is exposed to SP through mixed infections and/or incorrect diagnosis [20-22]. Regarding SNPs in the Pvdhfr, the double mutant FR2TN which is common in Uttar Pradesh (34\%) and Assam (50\%) [49], was the major mutant haplotype in the current study (47\%) as well. The triple and quadruple Pvdhfr mutant haplotypes associated with high levels of in vivo SP resistance [50] were not found, indicating limited levels of $P$. vivax SP resistance in the study area.

The SNP patterns observed in Pfcrt, Pfdhfr and Pvdhfr genes in Nepal are similar to the studies performed in India, especially in the states that share borders with Nepal $[37,43,49]$. This indicates that either the parasites are under similar drug pressure in both countries or the free movement of people for work and other purposes between these countries are responsible for carrying parasites with similar drug resistance profiles. In this study, high percentages $(85 \%)$ of the malaria positive were identified in males. Similar results were determined from Jhapa in 2005 (73\%) and 2007 (75\%) [26,51]. A study done in 2008 showed that around $37 \%$ of patients, particularly the males, had a history of a recent visit to India [52]. Although this study did not evaluate this aspect, it may be the possible cause for the higher percentage of infection in males and thus the similar patterns of SNPs in the resistance genes of $P$. falciparum and P. vivax.

A limitation to the present study is the small sample size. The majority of the samples collected on glass slides were found negative by PCR, which may be due to low parasitemia or misdiagnosis by microscopy or simply poor success in DNA extraction. Thus, the results should be interpreted with caution.

\section{Conclusions}

This study has determined low molecular prevalence of resistance to CQ and SP in P. vivax and a high level of CQ and SP resistance in P. falciparum in a limited number of samples from two districts in Nepal. Therefore, CQ is most likely still effective in the treatment of $P$. vivax infections, but this remains to be tested in vivo while the change to ACT against $P$. falciparum infection seems justified at molecular level.

\section{Acknowledgements}

We thank the patients who provided blood samples and the Nepal Health Research Council, which granted the ethical clearance for this study. We are grateful to the Copenhagen School of Global Health for funding the field visit to Nepal for sample collection. We would also like to thank Mala Ranawake, Administrative Officer, IWMI Headquarters, Sri Lanka for assisting in language correction and Ulla Abildtrup for her excellent technical assistance.

\section{Author details}

${ }^{1}$ Centre for Medical Parasitology, Department of International Health, Immunology and Microbiology, Faculty of Health Sciences, University of Copenhagen, Copenhagen, Denmark. ${ }^{2}$ Central Department of Microbiology, Tribhuvan University, Kathmandu, Nepal. ${ }^{3}$ Department of Agriculture and Ecology, Faculty of Life Sciences, University of Copenhagen, Copenhagen, Denmark.

\section{Authors' contributions}

SA carried out the sample collections, molecular analysis and drafted the manuscript. MLS and TTT participated in the design of the study, sequence alignment and data interpretation. MA ${ }^{1}, C M O K$ and ICB funded the study, participated in the design and coordination and data interpretation. MA $^{2}$ coordinated the sample collection. All authors read and approved the final manuscript.

\section{Competing interests}

The authors declare that they have no competing interests.

Received: 17 January 2011 Accepted: 1 April 2011

Published: 1 April 2011

\section{References}

1. Malaria-Disease Burden in SEA Region. [http://www.searo.who.int/EN/ Section10/Section21/Section340_4018.htm].

2. Tatem AJ, Smith DL, Gething PW, Kabaria CW, Snow RW, Hay SI: Ranking of elimination feasibility between malaria-endemic countries. Lancet 2010, 376:1579-1591.

3. Nepal-Malaria Situation in SEAR Countries. [http://www.searo.who.int/en/ Section10/Section21/Section340.htm].

4. Epidemiology \& Disease Control Division, Department of Health Services, Ministry of Health \& Population, Government of Nepal: National Malaria Treatment Protocol. 2009.

5. Epidemiology \& Disease Control Division, Department of Health Services, Ministry of Health \& Population, Government of Nepal: The Internal assessment of Malaria and Kala-azar Control Activities 2004, 2005 and 2006. 2007.

6. Farooq U, Mahajan RC: Drug resistance in malaria. J Vector Borne Dis 2004, 41:45-53.

7. White NJ: Antimalarial drug resistance. J Clin Invest 2004, 113:1084-1092.

8. Wongsrichanalai C, Pickard AL, Wernsdorfer WH, Meshnick SR: Epidemiology of drug-resistant malaria. Lancet Infect Dis 2002, 2:209-218. 
9. Wijeyaratne PM, Valecha N, Joshi AB, Singh D, Pandey S: An inventory on malaria drug resistance in Bangladesh, Bhutan, India and Nepal. Environment Health Project Activity Report 2005, 130:1-43.

10. Chand PB, Wijeyaratne PM, Pandey S, Ansari MA, Valecha N: Assessment of therapeutic efficacy of anti-malarial drug against uncomplicated Plasmodium falciparum malaria in the Indo-Nepal Border Jhapa district (Nepal) \& Darjeeling district, West Bengal (India). Journal of Nepal Health Research Council 2003, 1:59.

11. Marfurt J, de Monbrison F, Brega S, Barbollat L, Sie A, Goroti M, Reeder JC, Beck HP, Picot S, Genton B: Molecular markers of in vivo Plasmodium vivax resistance to amodiaquine plus sulfadoxine-pyrimethamine: mutations in pvdhfr and pvmdr1. J Infect Dis 2008, 198:409-417.

12. Durand R, Jafari S, Vauzelle J, Delabre JF, Jesic Z, Le Bras J: Analysis of pfcrt point mutations and chloroquine susceptibility in isolates of Plasmodium falciparum. Mol Biochem Parasitol 2001, 114:95-102.

13. Djimde A, Doumbo OK, Cortese JF, Kayentao K, Doumbo S, Diourte $Y$, Dicko A, Su X, Nomura T, Fidock DA: A molecular marker for chloroquineresistant falciparum malaria. NEJM 2001, 344:257-263.

14. Warhurst DC: Polymorphism in the Plasmodium falciparum chloroquineresistance transporter protein links verapamil enhancement of chloroquine sensitivity with the clinical efficacy of amodiaquine. Malar J 2003, 2:31.

15. Le Bras J, Durand R: The mechanisms of resistance to antimalarial drugs in Plasmodium falciparum. Fundamental \& Clinical Pharmacology 2003, 17:147-153.

16. Eldin de Pqcoulas P, Basco LK, Tahar R, Ouatas T, Mazabraud A: Analysis of the Plasmodium vivax dihydrofolate reductase-thymidylate synthase gene sequence. Gene 1998, 211:177-185.

17. Korsinczky M, Fischer K, Chen N, Baker J, Rieckmann K, Cheng Q: Sulfadoxine resistance in Plasmodium vivax is associated with a specific amino acid in dihydropteroate synthase at the putative sulfadoxinebinding site. Antimicrob Agents Chemother 2004, 48:2214-2222.

18. Cowman AF, Morry MJ, Biggs BA, Cross GA, Foote SJ: Amino acid changes linked to pyrimethamine resistance in the dihydrofolate reductasethymidylate synthase gene of Plasmodium falciparum. Proc Natl Acad Sci USA 1988, 85:9109-9113.

19. Wang P, Read M, Sims PFG, Hyde JE: Sulfadoxine resistance in the human malaria parasite Plasmodium falciparum is determined by mutations in dihydropteroate synthetase and an additional factor associated with folate utilization. Mol Microbiol 1997, 23:979-986.

20. Hawkins VN, Joshi H, Rungsihirunrat $\mathrm{K}, \mathrm{Na}$-Bangchang $\mathrm{K}$, Sibley $\mathrm{CH}$ : Antifolates can have a role in the treatment of Plasmodium vivax. Trends Parasitol 2007, 23:213-222.

21. Khatoon L, Baliraine FN, Bonizzoni M, Malik SA, Yan G: Short Report: Prevalence of antimalarial drug resistance mutations in Plasmodium vivax and $P$. falciparum from a malaria-endemic area of Pakistan. Am J Trop Med Hyg 2009, 81:525-528.

22. Valecha N, Joshi H, Eapen A, Ravinderan J, Kumar A, Surendra KP, Ringwald P: Therapeutic efficacy of chloroquine in Plasmodium vivax from areas with different epidemiological patterns in India and their Pvdhfr gene mutation pattern. Trans R Soc Trop Med Hyg 2006, 100:831-837.

23. Barnadas C, Tichit M, Bouchier C, Ratsimbasoa A, Randrianasolo L, Raherinjafy $R$, Jahevitra M, Picot $S$, Ménard D: Plasmodium vivax dhfr and dhps mutations in isolates from Madagascar and therapeutic response to sulphadoxine-pyrimethamine. Malar J 2008, 7:1-11.

24. Auliff A, Wilson DW, Russel B, Goa Ql, Chen N, Anh L, Maguire J, Bel D, O'Neil MT, CCheng QIN: Amino acid mutations in Plasmodium vivax DHFR and DHPS from several geographical regions and susceptibility to antifolate drugs. Am J Trop Med Hyg 2006, 75:617-621.

25. Alifrangis $M$, Lemnge MM, Ronn AM: Increasing prevalence of wildtypes in the dihydrofolate reductase gene of Plasmodium falciparum in an area with high levels of sulfadoxine/pyrimethamine resistance after introduction of treated bed nets. Am J Trop Med Hyg 2003, 69:238-243.

26. Thapa S, Hollander J, Linehan M, Cox-Singh J, Bista MB, Thakur GD, Davis WA, Davis TME: Comparison of artemether-lumefantrine with sulfadoxine-pyrimethamine for the treatment of uncomplicated falciparum malaria in Eastern Nepal. Am J Trop Med Hyg 2007. 77:423-430.

27. Wooden J, Kyes S, Sibley CH: PCR and strain identification in Plasmodium falciparum. Parasitol Today 1993, 9:303-305.
28. Alger J, Acosta MC, Lozano C, Velasquez C, Labrada LA: Stained smears as a source of DNA. Mem Inst Oswaldo Cruz 1996, 91:589-591.

29. Rupika R, Michael A, Priyanie A, Flemming K: Pre-elimination stage of malaria in Sri Lanka: assessing the level of hidden parasites in the population. Malar J 2010, 9:1-6.

30. Snounou G, Thaithongc S, Browna KN: High sensitivity of detection of human malaria parasites by the use of nested polymerase chain reaction. Mol Biochem Parasitol 1993, 61:315-320.

31. Suwanarusk R, Russell B, Chavchich M, Chalfein F, Kenangalem E, Kosaisavee V, Prasetyorini B, Piera KA, Barends M, Brockman A: Chloroquine resistant Plasmodium vivax: in vitro characterisation and association with molecular polymorphisms. PLoS One 2007, 2:1-9.

32. Schousboe ML, Rajakaruna RS, Salanti A, Hapuarachchi HC, Galappaththy GN, Bygbjerg IC, Amerasinghe PH, Konradsen F, Alifrangis M: Island-wide diversity in single nucleotide polymorphisms of the Plasmodium vivax dihydrofolate reductase and dihydropteroate synthetase genes in Sri Lanka. Malar J 2007, 6:28.

33. Alifrangis M, Enosse S, Pearce R, Drakeley C, Roper C, Khalil IF, Nkya WMMM, Ronn AM, Theander TG, Bygbjerg IC: A simple, high-throughput method to detect Plasmodium falciparum single nucleotide polymorphisms in the dihydrofolate reductase, dihydropteroate synthase, and $P$. falciparum chloroquine resistance transporter genes using polymerase chain reaction-and enzyme-linked immunosorbent assay-based technology. Am J Trop Med Hyg 2005, 72:155-162.

34. Duraisingh MT, Roper C, Walliker D, Warhurst DC: Increased sensitivity to the antimalarials mefloquine and artemisinin is conferred by mutations in the pfmdr1 gene of Plasmodium falciparum. Mol Microbiol 2000, 36:955-961.

35. Humphreys GS, Merinopoulos I, Ahmed J, Whitty CJM, Mutabingwa TK, Sutherland CJ, Hallett RL: Amodiaquine and artemether-lumefantrine select distinct alleles of the Plasmodium falciparum mdr1 gene in Tanzanian children treated for uncomplicated malaria. Antimicrob Agents Chemother 2007, 51:991-997.

36. Malaria-Drug Resistance. [http://www.searo.who.int/EN/Section10/ Section21/Section340_4039.htm].

37. Keen J, Farcas GA, Zhong K, Yohanna S, Dunne MW, Kain KC: Real-time PCR assay for rapid detection and analysis of PfCRT haplotypes of chloroquine-resistant Plasmodium falciparum isolates from India. J Clin Microbiol 2007, 45:2889-2893.

38. Laufer MK, Thesing PC, Eddington ND, Masonga R, Dzinjalamala FK, Takala SL, Taylor TE, Plowe CV: Return of chloroquine antimalarial efficacy in Malawi. NEJM 2006, 355:1959-1966.

39. Alifrangis $M$, Lusingu JP, Mmbando $B$, Dalgaard MB, Vestergaard LS, Ishengoma D, Khali IF, Theander TG, Lemnge MM, Bygbjerg IC: Five-year surveillance of molecular markers of Plasmodium falciparum antimalarial drug resistance in Korogwe District, Tanzania: accumulation of the 581G mutation in the $P$. falciparum dihydropteroate synthase gene. Am J Trop Med Hyg 2009, 80:523-527.

40. Sisowath C, Ferreira PE, Bustamante LY, Dahlstrom S, Martensson A, Bjorkman A, Krishna S, Gil JP: The role of pfmdr1 in Plasmodium falciparum tolerance to artemether lumefantrine in Africa. Trop Med Int Health 2007, 12:736-742.

41. Gama BE, Oliveira NKA, Souza JM, Daniel-Ribeiro CT, Ferreira-da-Cruz MF: Characterisation of pvmdr1 and pvdhfr genes associated with chemoresistance in Brazilian Plasmodium vivax isolates. Mem Inst Oswaldo Cruz 2009, 104:1009-1011.

42. Barnadas C, Ratsimbasoa A, Tichit M, Bouchier C, Jahevitra M, Picot S, Ménard D: Plasmodium vivax resistance to chloroquine in Madagascar: clinical efficacy and polymorphisms in pvmdr1 and pvcrt-o genes. Antimicrob Agents Chemother 2008, 52:4233.

43. Ahmed A, Bararia D, Vinayak S, Yameen M, Biswas S, Dev V, Kumar A, Ansari MA, Sharma YD: Plasmodium falciparum isolates in India exhibit a progressive increase in mutations associated with sulfadoxinepyrimethamine resistance. Antimicrob Agents Chemother 2004, 48:879-889.

44. Ahmed A, Lumb V, Das MK, Dev V: Prevalence of mutations associated with higher levels of sulfadoxine-pyrimethamine resistance in Plasmodium falciparum isolates from Car Nicobar Island and Assam, India. Antimicrob Agents Chemother 2006, 50:3934-3938.

45. Picot S, Olliaro P, de Monbrison F, Bienvenu AL, Price RN, Ringwald P: A systematic review and meta-analysis of evidence for correlation 
between molecular markers of parasite resistance and treatment outcome in falciparum malaria. Malar J 2009, 8:89.

46. Garg S, Saxena V, Kanchan S, Sharma P, Mahajan S, Kochar D, Das A: Novel point mutations in sulfadoxine resistance genes of Plasmodium falciparum from India. Acta Trop 2009, 110:75-79.

47. Sedigheh Z, Mandana A, Ahmad R, Navid D: Prevalence of mutations associated with antimalarial drugs in Plasmodium falciparum isolates prior to the introduction of sulphadoxine-pyrimethamine as first-line treatment in Iran. Malar J 2007, 6:148.

48. Wijeyaratne PM, Chand PB, Valecha N, Shahi B, Adak T, Ansari MA, Jha J, Pandey S, Bannerjee S, Bista MB: Therapeutic efficacy of antimalarial drugs along the eastern Indo-Nepal border: a cross-border collaborative study. Trans R Soc Trop Med Hyg 2005, 99:423-429.

49. Alam MT, Bora H, Bharti PK, Saifi MA, Das MK, Dev V, Kumar A, Singh N, Dash AP, Das B: Similar trends of pyrimethamine resistance-associated mutations in Plasmodium vivax and $P$. falciparum. Antimicrob Agents Chemother 2007, 51:857-863.

50. Imwong M, Pukrittakayamee S, Looareesuwan S, Pasvol G, Poirreiz J, White NJ, Snounou G: Association of genetic mutations in Plasmodium vivax $\mathrm{dhfr}$ with resistance to sulfadoxine-pyrimethamine: geographical and clinical correlates. Antimicrob Agents Chemother 2001, 45:3122-3127.

51. Parajuli K, Hanchana S, Imwong M, Pukrittayakayamee S, Ghimire P: Comparative evaluation of microscopy and polymerase chain reaction (PCR) for the diagnosis in suspected malaria patients of Nepal. Nepal Med Coll J 2009, 11:23-27.

52. Banjara MR, Sirawaraporn W, Petmitr S, Imwong M, Joshi AB, Chavalitshewinkoon-Petmitr P: Characteristics and risk factors of Plasmodium falciparum malaria in Eastern and Central Nepal. Kathmandu University Medical Journal 2010, 7:378-382.

53. Nepal-Malaria Situation in SEAR Countries. [http://www.who.int/malaria/ publications/country-profiles/2008/mal2008-nepal-en.pdf].

54. Department of Health Services, Ministry of Health \& Population, Government of Nepal: 2010, Annual Report 2008/2009.

doi:10.1186/1475-2875-10-75

Cite this article as: Ranjitkar et al: Prevalence of molecular markers of anti-malarial drug resistance in Plasmodium vivax and Plasmodium falciparum in two districts of Nepal. Malaria Journal 2011 10:75.

\section{Submit your next manuscript to BioMed Central and take full advantage of:}

- Convenient online submission

- Thorough peer review

- No space constraints or color figure charges

- Immediate publication on acceptance

- Inclusion in PubMed, CAS, Scopus and Google Scholar

- Research which is freely available for redistribution

Submit your manuscript at www.biomedcentral.com/submit
Biomed Central 